\title{
Chitin Deacetylases Are Required for Epichloë festucae Endophytic Cell Wall Remodeling During Establishment of a Mutualistic Symbiotic Interaction with Lolium perenne
}

\author{
Nazanin Noorifar, ${ }^{1}$ Matthew S. Savoian, ${ }^{1}$ Arvina Ram, ${ }^{1}$ Yonathan Lukito, ${ }^{1}$ Berit Hassing, ${ }^{1,2}$ \\ Tobias W. Weikert, ${ }^{3}$ Bruno M. Moerschbacher, ${ }^{3}$ and Barry Scott ${ }^{1,2, \dagger}$ \\ ${ }^{1}$ School of Fundamental Sciences, Massey University, Palmerston North 4442, New Zealand \\ ${ }^{2}$ Bioprotection Research Centre, Massey University, Palmerston North 4442, New Zealand \\ ${ }^{3}$ Institute for Biology and Biotechnology of Plants, Westfälische Wilhelms-Universität, Münster, Germany
}

Accepted 5 May 2021.

\begin{abstract}
Epichlö festucae forms a mutualistic symbiotic association with Lolium perenne. This biotrophic fungus systemically colonizes the intercellular spaces of aerial tissues to form an endophytic hyphal network and also grows as an epiphyte. However, little is known about the cell wall-remodeling mechanisms required to avoid host defense and maintain intercalary growth within the host. Here, we use a suite of molecular probes to show that the $E$. festucae cell wall is remodeled by conversion of chitin to chitosan during infection of $L$. perenne seedlings, as the hyphae switch from free-living to endophytic growth. When hyphae transition from endophytic to epiphytic growth, the cell wall is remodeled from predominantly chitosan to chitin. This conversion from chitin to chitosan is catalyzed by chitin deacetylase. The genome of $\boldsymbol{E}$. festucae encodes three putative chitin deacetylases, two of which $(c d a A$ and $c d a B)$ are expressed in planta. Deletion of either of these genes results in disruption of fungal intercalary growth in the intercellular spaces of plants infected with these mutants. These results establish that these two genes are required for maintenance of the mutualistic symbiotic interaction between $E$. festucae and L. perenne.
\end{abstract}

Keywords: chitin, chitosan, endophyte, Epichlö̈festucae, molecular probes

Fungal species from the genus Epichlö (Ascomycota, Clavicipitaceae) are symbionts of cool-season grasses that form systemic hyphal networks within the apoplastic spaces of host aerial tissues (Schardl et al. 2004, 2009). These infections are usually asymptomatic and are generally regarded as mutualistic because the

${ }^{\dagger}$ Corresponding author: B. Scott: d.b.scott@massey.ac.nz

Funding: This research was supported by a grant from the Tertiary Education Commission (number RM20918) to the Bio-Protection Research Centre and by Massey University. N. Noorifar was supported by a Massey University PhD scholarship and B. Scott by an Alexander von Humboldt Research Award.

*The $\boldsymbol{e}$-Xtra logo stands for "electronic extra" and indicates there are supplementary materials published online.

The author(s) declare no conflict of interest.

(c) (1) () () Copyright $\odot 2021$ The Author(s). This is an open access article (c) fungal endophyte synthesizes a range of bioactive secondary metabolites that protect the host against biotic stress (Schardl et al. 2013; Tanaka et al. 2012). In return, the host provides a source of nutrients for the fungus either directly from the apoplastic space or by way of specialized transport processes between the hyphae and the attached plant cells (Christensen et al. 2002; Hinton and Bacon 1985). The stable association between E. festucae and Lolium perenne (perennial ryegrass) is now established as a model experimental system for studying this important above-ground fungalgrass symbiotic interaction (Scott et al. 2012; Scott et al. 2018).

E. festucae establishes a hyphal network within the aerial tissue of ryegrass by two distinct growth mechanisms (Scott et al. 2012). In the true stem, hyphae grow between the tightly packed cells by tip growth, lateral branching, and hyphal cell-to-cell fusion to form a hyphal network within these tissues. From here, hyphae ramify into the leaf primordia and axillary buds, which give rise to new leaves and shoots, respectively (Christensen and Voissey 2007). Once hyphae colonize leaf primordia, which comprise sheath and blade zones of cell division, they become attached to the plant cell wall. As the leaf cells expand from these cell division zones, the hyphae are stretched, triggering a unique pattern of hyphal growth known as intercalary growth (Christensen et al. 2008). This ensures the hyphae avoid mechanical shear as the host cells, to which they are firmly attached, expand rapidly (Voisey 2010). However, we have little understanding of how the fungal cell wall is remodeled to enable this pattern of growth in the plant or how $E$. festucae avoids eliciting a host immune response from direct physical contact between the fungal and plant cell walls.

Fungal cell walls are comprised of a complex matrix of polysaccharides and proteins, including $\beta$-glucans ( $\beta$-1,3-glucan and $\beta$-1,6-glucan), $\alpha$-glucans ( $\alpha$-1,3-glucan and $\alpha$-1,4-glucan), chitin and mannan (Pérez and Ribas 2004; Latgé 2007). However, the composition and amount of each of these components vary considerably among different fungal species, and between different fungal structures, such as hyphae, conidia, or capsules (Erwig and Gow 2016; Fujikawa et al. 2009; Gow et al. 2017; Hopke et al. 2018). Chitin, a linear homopolymer of $\beta$-1,4-linked $N$-acetyl-Dglucosamine (GlcNAc) monomers, is a structurally important component of the cell wall (Bowman and Free 2006; Latgé 2007, 2010). It is also recognized as an important microbeassociated molecular pattern that will elicit pattern-triggered immunity (PTI), unless it is masked, modified, or sequestered to prevent interaction with plant chitin receptors (Boller and Felix 2009; Boutrot and Zipfel 2017; Zipfel and Oldroyd 2017). Fungal secretion of apoplastic effectors, which bind to chitin oligomers in the apoplastic space or to the fungal cell wall itself is a 
well-characterized mechanism for preventing elicitation of a PTI response (de Jonge et al. 2010; van Esse et al. 2007). Other strategies used by fungi to evade plant immunity include masking of chitin with $\alpha$-1,3-glucan (Fujikawa et al. 2012) or conversion of chitin to chitosan by chitin deacetylases (Cord-Landwehr et al. 2016; El Gueddari et al. 2002; Gao et al. 2019; Nampally et al. 2012; Xu et al. 2020). While chitin appears to be an important component of the cell wall of E. festucae grown in axenic culture, it is not detected in the cell wall of endophytic hyphae, although it is clearly present in septa, as seen following infiltration of leaf tissue with the chitin-specific wheat germ agglutinin-AlexaFluor 488 (WGA-AF488) probe (Becker et al. 2015, 2016; Eaton et al. 2015).

Besides growing as an endophyte, E. festucae is also capable of epiphytic growth across the surface of a grass leaf (Christensen et al. 1997; Moy et al. 2000). These epiphytic hyphae arise from and remain connected to endophytic hyphae within the leaf. Endophytic hyphae colonize the epidermal cells beneath the cuticle in this leaf zone, where they differentiate to form an appressorium-like structure called an expressorium that facilitates cuticle penetration and exit of the hyphae onto the leaf surface (Becker et al. 2016). Dramatically, the entire cell wall of these epiphytic hyphae becomes labeled with WGA-AF488 within a few cell divisions following emergence, suggesting chitin becomes a dominant component of the cell wall.

These observations suggest that the chitin/chitosan component of the E. festucae cell wall is modified during the transition from free-living to endophytic hyphae and from endophytic to epiphytic hyphae. To test this hypothesis, we employ a range of molecular probes to identify whether chitin or chitosan is present in the cell wall of E. festucae at these different developmental stages and test genetically whether chitin deacetylases are required for establishment and maintenance of this mutualistic symbiotic interaction.

\section{RESULTS}

\section{Endophytic and epiphytic hyphal cell walls have distinct chitin staining profiles.}

Tissue from $L$. perenne seedlings at an early stage of infection with $E$. festucae Fl1 were stained with WGA-AF488 and aniline blue, which stain chitin and hyaline fungal structures, respectively. Confocal laser scanning microscopy (CLSM) showed that only the septa of endophytic hyphae were labeled with WGA-AF488, while the hyphal cell wall was labeled with aniline blue (Fig. 1 A through D). In contrast, both the cell wall and septa of epiphyllous hyphae around the site of infection were labeled with WGAAF488 (Fig. 1A through C). Similarly, labeling of infected plant sheath samples with chitin-binding protein (CBP) (Fuenzalida et al. 2014) showed that only fungal septa of endophytic hyphae labeled with this chitin-specific probe (Fig. 1E through G). This suggests that chitin is either masked or absent from the cell walls of endophytic hyphae.

Strikingly, labeling of leaf sheath samples with WGA-AF488 and aniline blue showed that epiphytic hyphae near the expressorium emergence point on the leaf surface had a combination of both staining patterns. A transition was observed from septaonly WGA-AF488 labeling at the emergence point to a progressively more homogeneous labeling of the hyphal cell walls outside of the plant (Fig. 2). This suggests that the cell wall of E. festucae is remodeled during the transition from endophytic to epiphytic growth.

\section{Endophytic hyphal cell walls can be labeled with a chitosan-specific probe.}

Given that conversion of chitin to chitosan in the cell walls of pathogenic fungi is a known mechanism for evading a host defense response (El Gueddari et al. 2002; Nampally et al. 2012), we hypothesized that a similar change occurs in the cell wall of E. festucae endophytic hyphae. To test this hypothesis, we probed fungal endophytic hyphae with chitosan affinity protein (CAP), which selectively recognizes chitosan (Nampally et al. 2012). CLSM analysis of the plant cell division zone and leaf primordia revealed that CAP exclusively labeled the endophyte cell wall in this zon, and did not label septa (Fig. 3A and B). A similar labeling pattern was observed for endophytic hyphae within the leaf sheath, with the hyphal cell wall labeled along its full visible length with this chitosan-specific probe and no signal observed in septa (Fig. 3C and D).

\section{The $E$. festucae Fl1 genome encodes three chitin deacetylases.}

We analyzed the genome of E. festucae for genes encoding chitin deacetylases, enzymes that catalyze the conversion of chitin to chitosan (Christodoulidou et al. 1996). A tBLASTn search of the E. festucae Fl1 genome sequence using a Magnaporthe oryzae chitin deacetylase (CDA) protein sequence queries (MGG_12939, MGG_14966, MGG_09159, MGG_04172, MGG_08774, MGG_01868, MGG_08356, MGG_05023, MGG_04704, and MGG_03461) (Geoghegan and Gurr 2016) identified three chitin deacetylase genes, EfM3.035615, EfM3.030650, and EfM3.042050 (Schardl et al. 2013), which were designated $c d a A$, $c d a B$, and $c d a C$, respectively. These share 24 to $56 \%$ identity with $M$. oryzae chitin deacetylase proteins (Supplementary Table $\mathrm{S} 1)$. The domain structure of the encoded $\mathrm{CdaA}, \mathrm{CdaB}$, and $\mathrm{CdaC}$ proteins was determined using InterProScan (Blum et al. 2021), showing that all three proteins contain polysaccharide chitin deacetylase (Pfam 01522) domains but no chitin binding (Pfam 00187) domains (Supplementary Fig. S1). In addition, CdaA and $\mathrm{CdaB}$ contain an $\mathrm{N}$-terminal signal peptide that targets proteins toward the classical protein secretion pathway, although $\mathrm{CdaB}$ is also predicted to contain a transmembrane helix, as found in the M. oryzae (Geoghegan and Gurr 2016) and Trichoderma atroviride (Kappel et al. 2020) homologs CDA8 and CDA2, respectively. An alignment of the three putative $E$. festucae chitin deacetylases with the structurally characterized Streptococcus pneumoniae peptidoglycan deacetylase and Colletotrichum lindemuthianum chitin deacetylase confirmed that the $S$. pneumoniae catalytic residues D275 and R364 as well as H417 and D391, which comprise the two charged relay pairs, and the zinc (Zn)-binding triad of D276, $\mathrm{H} 326$, and $\mathrm{H} 330$ are conserved in the E. festucae sequences (Supplementary Fig. S2) (Blair et al. 2005, 2006).

To gain insight into which of the three chitin deacetylase genes might be important for symbiosis, the expression of each of these genes was compared between hyphae growing in planta and in axenic culture (Hassing et al. 2019; Winter et al. 2018). This analysis revealed that $c d a A$ was significantly upregulated in planta compared with axenic culture, whereas $c d a B$ had comparable levels of expression under the two physiological conditions. $c d a C$ was not expressed under either condition (Supplementary Table $\mathrm{S} 2$ ). We therefore generated a deletion mutant of $c d a A$ and analyzed the axenic culture and plant interaction phenotypes of three independently isolated mutants, $\triangle c d a A$ \#28, \#41, and \#49 (Supplementary Fig. S3).

\section{Phenotype analysis of $\Delta c d a A$ mutant.}

Radial growth and morphology of $\Delta c d a A$ strains on potato dextrose agar (PDA) media was indistinguishable from the wild-type (WT) strain. Widefield epifluorescence light microscopy analysis of cultures grown on water agar and stained with Calcofluor white showed that the morphology and frequency of hyphal bundles, hyphal cell-to-cell fusions, and hyphal coils was similar between $\triangle c d a A$ and WT (Supplementary Fig. S4). We next examined the role of $c d a A$ in the symbiotic interaction between $E$. festucae 
and L. perenne. Cultures of WT and $\Delta c d a A$ were inoculated into $L$. perenne seedlings and the interaction phenotype was examined at 10 weeks postinoculation (wpi). No significant differences in tiller height or tiller number were observed between plants infected with WT and the $\triangle c d a A$ mutants (Fig. 4A). However, CLSM analysis revealed that $\Delta c d a A$ hyphae were less abundant and exhibited a dramatically different cellular phenotype compared with WT (Fig. 5). In contrast to WT, which had a highly restricted form of growth, with each intercellular space containing a single hypha running parallel to the leaf axis, with occasional fusion of lateral hyphal branches, the hyphae of the $\Delta c d a A$ mutants were swollen and occasionally formed dense convoluted structures (Fig. 5; Supplementary Fig. S5). Analysis of relative endophyte biomass was performed by quantitative PCR (qPCR), using the ratio of the single-copy E. festucae pacC gene (Lukito et al. 2015) to the single-copy L. perenne LpCCRl gene (McInnes et al. 2002). This showed no significant difference in the degree of host leaf sheath and blade colonization between the $\triangle c d a A$ mutant and WT (Supplementary Fig. S6). Introduction of the WT $c d a A$ allele into $\Delta c d a A$ complemented these in planta cellular phenotypes (Fig. 6), confirming that the defects were specific to the deletion of $c d a A$.

\section{Phenotype analysis of $\Delta c d a B$ single and $\Delta c d a A \Delta c d a B$} double mutants.

Given the relatively mild whole-plant interaction phenotype observed following infection with $\triangle c d a A$, we generated $\Delta c d a B$ single (\#17 and \#22) and $\Delta c d a A \Delta c d a B$ double (\#18 and \#30)
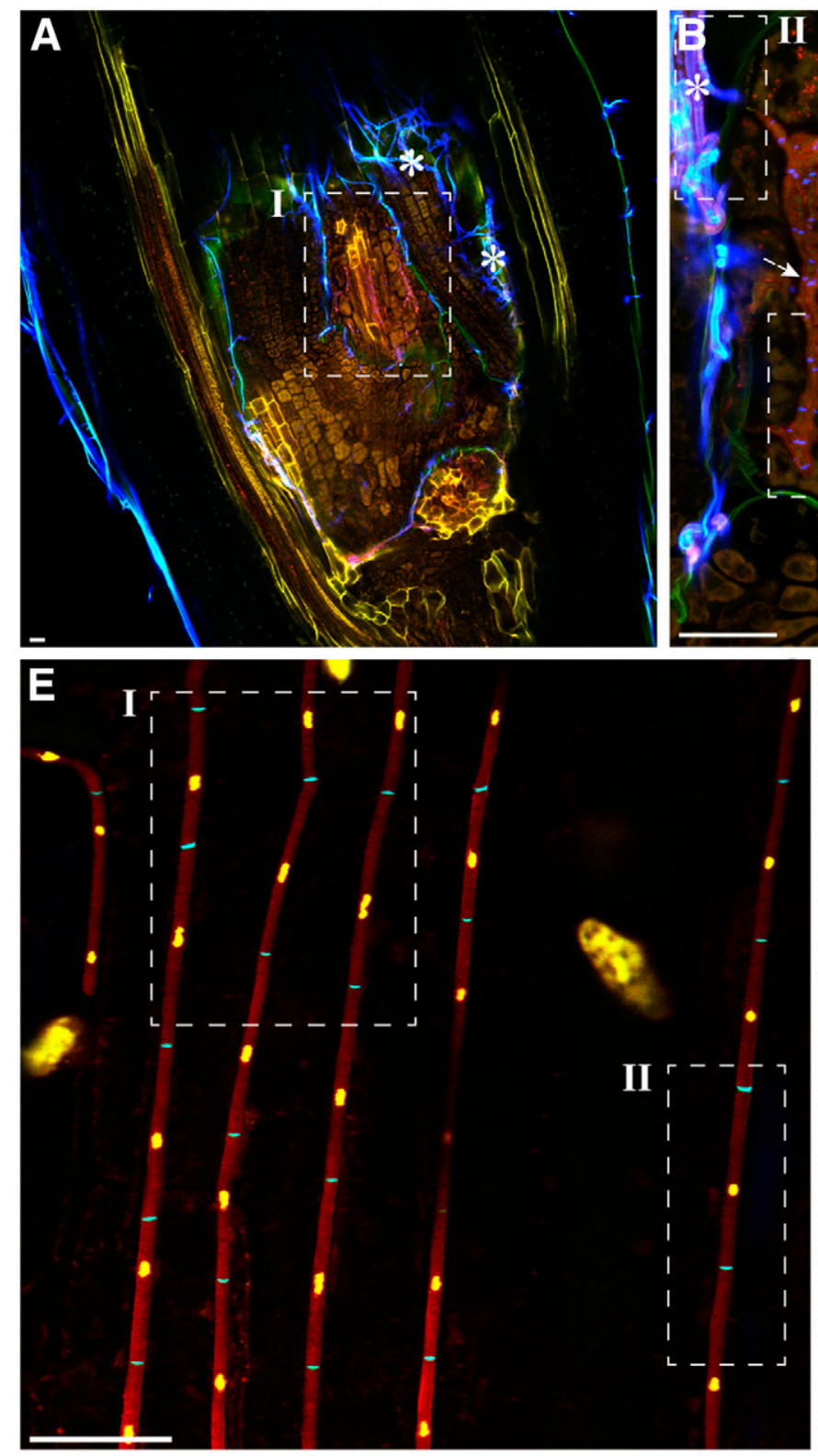

II
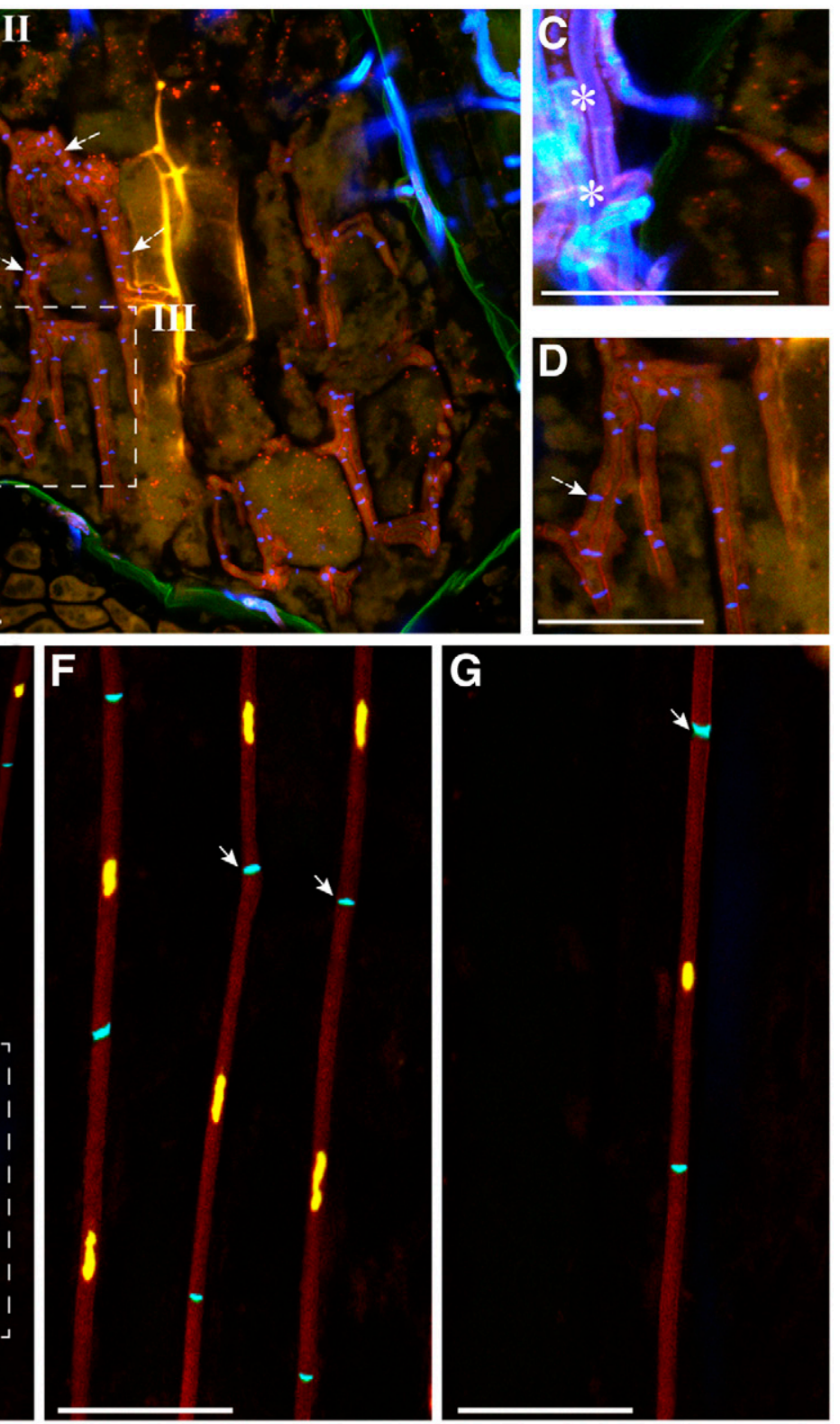

G

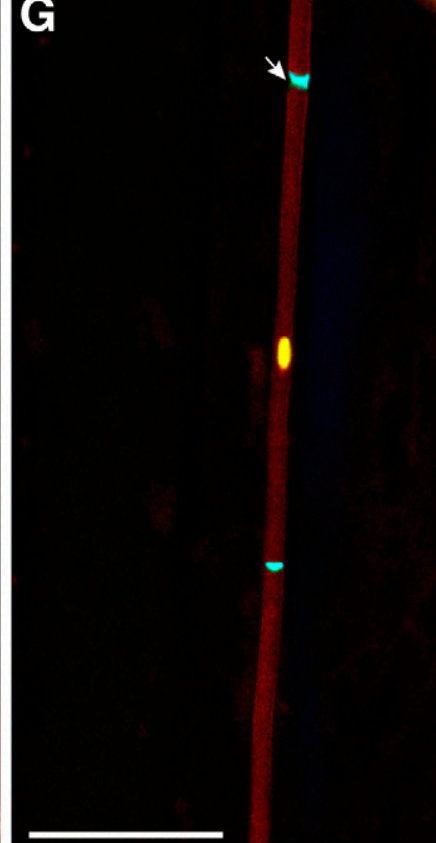

Fig. 1. Labeling of Epichloë festucae hyphae at the site of inoculation and in mature leaf sheath tissue of Lolium perenne plants, using chitin-specific molecular probes. A through D, Plant tissue was incubated with either wheat germ agglutinin-AlexaFluor 488 (WGA-AF488) or E through G, with chitin binding protein (cyan), propidium iodide (yellow) and aniline blue (red). A, L. perenne seedling infected with E. festucae wild-type Fl1 (WT) 2 weeks postinoculation showing epiphyllous hyphae (asterisks) stained with WGA-AF488 (blue pseudocolor). The rectangle labeled I outlines endophytic hyphae colonizing the seedling meristem zone stained with aniline blue (red pseudocolor) and chitin in cell-wall septa stained with WGA-AF488 (blue pseudocolor). B, Higher magnification of I in panel A, showing plant meristem colonization. C and D, Higher magnification of II and III in panel B, indicating epiphyllous (asterisk) and endophytic hyphae respectively. E, Longitudinal section of $L$. perenne leaf sheath tissue infected with WT 10 weeks postinoculation, stained with chitin binding protein (cyan), propidium iodide (yellow), and aniline blue (red). F, Higher magnification of I in panel E. G, Higher magnification of II in panel E. Arrows identify fungal septa. Images were generated by maximum intensity projection of confocal z-stacks. Bar $=20 \mu \mathrm{m}$. 
mutants to assess how the loss of both deacetylase genes might affect axenic culture growth and plant interaction phenotypes (Supplementary Fig. S7). Radial growth and morphology of $\triangle c d a B$ and $\triangle c d a A \Delta c d a B$ mutants on PDA media were indistinguishable from the WT strain. Epifluorescence light microscopy analysis of cultures grown on water agar and stained with Calcofluor white showed that $\Delta c d a B$ and $\Delta c d a A \Delta c d a B$ mutants form hyphal bundles, undergo hyphal cell-to-cell fusion, and form hyphal coils with the same morphology and frequency observed for the WT (Supplementary Fig. S8). However, the cell-wall integrity of the $\Delta c d a A \Delta c d a B$ double mutant appears to be compromised, as they frequently formed intrahyphal hyphae (Fig. 7).

In contrast to the $\Delta c d a A$ mutant, the $\Delta c d a B$ mutant had a strong plant interaction phenotype, with the tiller length of infected plants significantly reduced compared with plants infected with WT (Fig. 4). Surprisingly, the phenotype of plants infected with the $\triangle c d a A \Delta c d a B$ double mutants were not noticeably different from WT; while some plants had shorter tillers than WT, there was no significant overall difference. This difference in whole-plant interaction phenotype is most likely due to differences in host colonization, as the endophyte biomass in both leaf sheath and blade was significantly greater than that of WT for the $\Delta c d a B$ single mutant but not for the $\Delta c d a A \Delta c d a B$ double mutant (Supplementary Fig. S6). Analysis of the cellular phenotype by CSLM revealed a striking cellular phenotype for both mutants, with hyphae showing an irregular pattern of growth compared with WT and frequently forming very complex convoluted structures (Fig. 5; Supplementary Fig. S5). These hyphal growth defects were particularly prominent for the $\Delta c d a B$ single mutant. Introduction of the WT $c d a B$ allele into $\Delta c d a B$ complemented these in planta cellular phenotypes (Fig. 6). These hyphal morphologies were never observed in the WT, indicating that deletion of these genes results in disruption of intercalary growth within the host leaf tissue. However, even with deletion of both genes, the cell walls of endophytic hyphae were still depleted of chitin (Fig. 5; Supplementary Fig. S5). This absence of chitin is unlikely to be due to depletion of the third chitin deacetylase, i.e., $\mathrm{CdaC}$, as the level of expression of $c d a C$ was beyond the limit of detection ( $\mathrm{Cp}$ values of $>35)$ in WT and the $\Delta c d a A$, $\Delta c d a B$, or $\Delta c d a A \Delta c d a B$ mutant backgrounds (Supplementary Fig. S9).

\section{DISCUSSION}

For phytopathogenic and symbiotic fungi to establish a compatible interaction with their host plant, it is crucial that the cell-wall components of the fungus that elicit a host defense response, such as chitin and $\beta$-glucans, do not interact with the corresponding host receptors (Fesel and Zuccaro 2016; Sánchez-Vallet et al. 2015). Secretion of fungal effectors into the apoplastic space is a well-characterized mechanism for preventing elicitation of a pathogen-associated molecular pattern (PAMP) PTI response (de Jonge et al. 2010; Ma et al. 2018; van Esse et al. 2007; Wawra et al. 2016). Other strategies used by fungi to evade plant immunity include conversion of one or both cell-wall chitin and cell wall-derived chitin oligomers to chitosan by chitin deacetylases (Cord-Landwehr et al. 2016; El Gueddari et al. 2002; Gao et al. 2019; Nampally et al. 2012) and the masking of chitin with $\alpha$-1,3-glucan (Fujikawa et al. 2012). Here, we show that infection of $L$. perenne seedlings with $E$. festucae results in conversion of chitin to chitosan as the hyphae switch from free-living to endophytic growth. Similarly, chitin becomes predominant in the fungal cell wall as hyphae transition from endophytic to epiphytic growth.

By probing the structure of the E. festucae cell wall in infected plant tissues using the chitin-specific probe WGA-AF488, we found this probe stains only the septa of endophytic hyphae but decorates the entire cell wall of epiphytic hyphae (Becker et al. 2016). The absence of this probe from the endophytic cell wall is unlikely to be due to inaccessibility due to chitin masked by $\alpha-1,3$ glucan (Fujikawa et al. 2012), as there is no gene encoding an $\alpha-1,3$ glucan synthase in the E. festucae genome (Becker et al. 2015). However, there are other cell-wall appositions that can mask chitin (Freytag and Mendgen 1991). Also, chitin sources internal to the fungal cell were uniformly labeled with WGAAF488, as observed for septa and the cell walls of intrahyphal hyphae in some symbiotic mutants (Becker et al. 2015, 2016; Eaton et al. 2015). To better understand the changes in cell-wall chitin during the developmental transitions that accompany entry and exit of E. festucae into leaf tissue, we employed chitosanand chitosan-specific molecular probes (Fuenzalida et al. 2014; Nampally et al. 2012). Infiltration of leaf tissue with the chitosan probe CAP resulted in the labeling of E. festucae cell walls but not
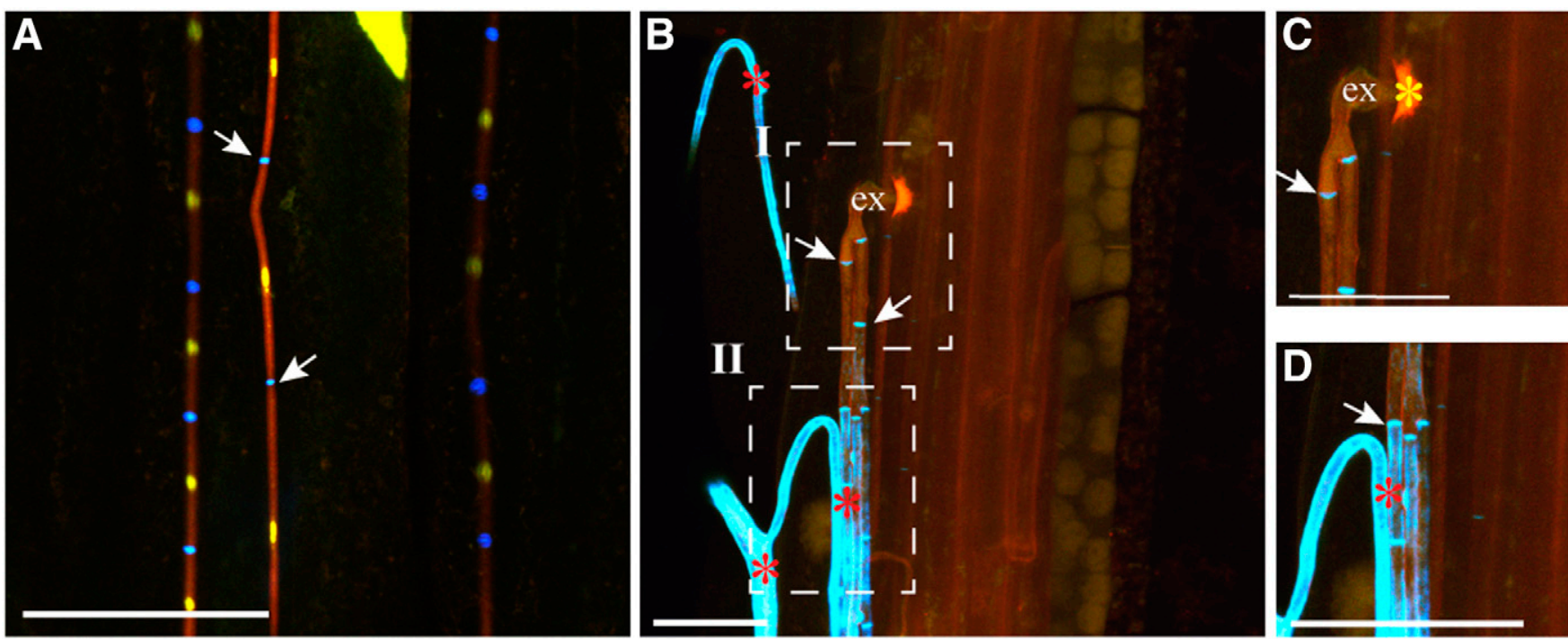

Fig. 2. Wheat germ agglutinin-AlexaFluor 488 (WGA-AF488) labeling of endophytic and epiphyllous hyphae of Epichlö festucae at the site of expressoriummediated exit from a leaf of Lolium perenne. A, E. festucae Fl1 endophytic hyphae stained with aniline blue (red), chitin in cell-wall septa with WGA-AF488 (blue), and fungal and plant nuclei with propidium iodide (yellow). B, E. festucae Fl1 expressorium (ex). The epiphyllous hyphae (red asterisk) stained with WGA-AF488 (blue). C and D, Higher magnification of (I) and (II) showing the expressorium (ex), emergence point (yellow asterisk) and epiphyllous hyphae (red asterisk). White arrows identify fungal septa. Images were generated by maximum intensity projections of confocal z-stacks. Bar $=20 \mu \mathrm{m}$. 
septa of hyphae growing between the tightly packed meristematic cells at the base of the leaves and in the intercellular spaces of mature leaf sheath tissue. This indicates that chitosan rather than chitin predominates in the cell wall of endophytic hyphae, regardless of the host aerial tissue type. In contrast, infiltration of leaf tissue with a second chitin binding probe, CBP, only labeled the septa of endophytic hyphae, as previously observed for the WGA-AF488 probe (Becker et al. 2015; Eaton et al. 2015). Similarly, WGA-AF488 stained the entire cell wall of epiphyllous hyphae, suggesting that chitin predominates in the cell wall following expressorium-mediated exit of endophytic hyphae onto the leaf surface. Interestingly, complete restoration of chitin presence in the cell wall takes several cell divisions following exit of the endophytic hyphae from the leaf cuticle (Becker et al. 2016). A number of phytopathogenic fungi have also been shown to undergo remodeling of the cell wall from chitin to chitosan during host infection (El Gueddari et al. 2002; Nampally et al. 2012). The presence of chitosan rather than chitin in the cell wall of endophytic hyphae is a potential mechanism for E. festucae to avoid a host immune response, given that chitosan with a sufficiently low fraction of acetylation is a much weaker PAMP than chitin and also a poorer substrate for chitinases, resulting in reduced levels of putatively PAMP-active cell-wall polymer fragments (CordLandwehr et al. 2016; Gubaeva et al. 2018; Vander et al. 1998).

Conversion of chitin to chitosan is catalyzed by chitin deacetylase, which was first biochemically characterized from Mucor
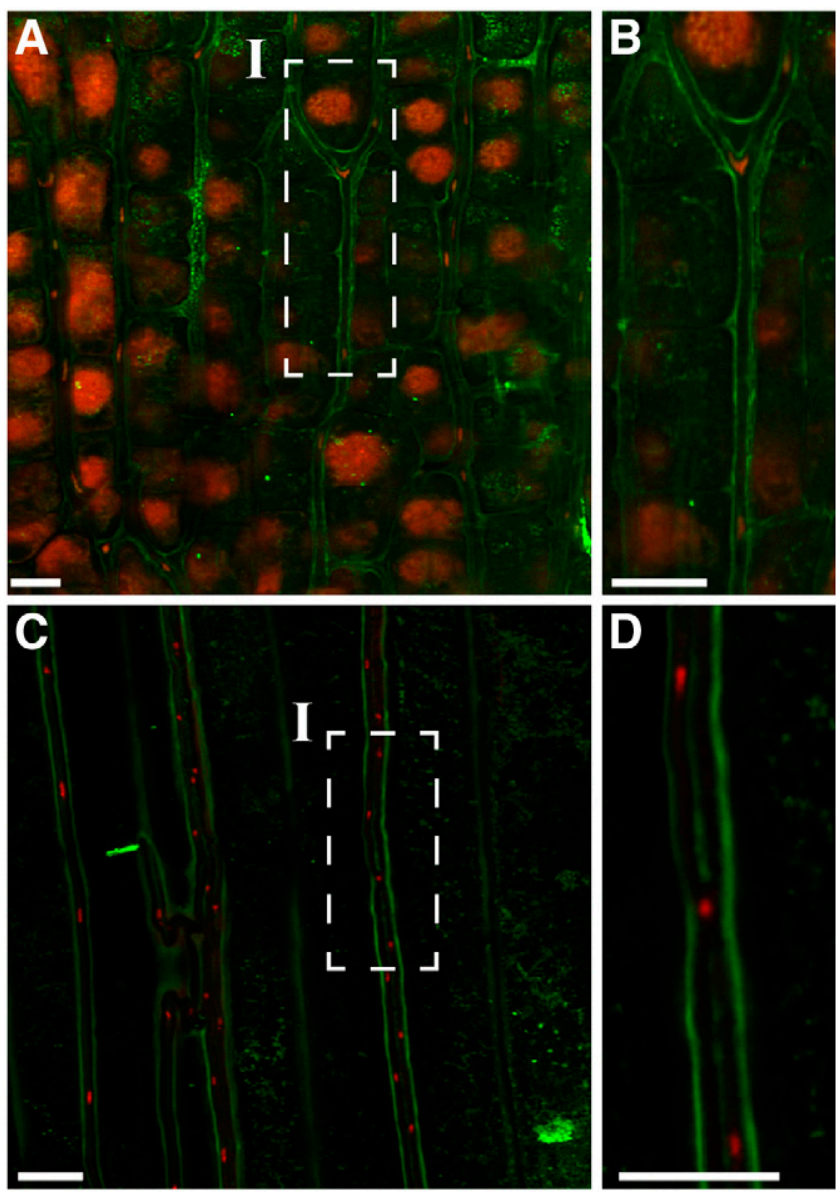

Fig. 3. Epichlö festucae endophytic hyphae in leaf tissue of Lolium perenne probed with chitosan affinity protein. Fungal cell wall labeled with chitosan affinity protein (CAP) (green) and fungal nuclei stained with propidium iodide (red). A and B, Hyphal labeling with CAP in leaf tissue at base of tiller and $\mathbf{C}$ and $\mathbf{D}$, in leaf sheath tissue. B and D show a higher magnification image of I from panels $\mathrm{A}$ and $\mathrm{C}$, respectively. Images were generated by maximum intensity projection of confocal z-stacks. Bar $=10 \mu \mathrm{m}$. rouxii (Kafetzopoulos et al. 1993) and was then genetically characterized in Saccharomyces cerevisiae, in which there are two functionally redundant copies of the gene (Christodoulidou et al. 1996, 1999). Analysis of the genome of $E$. festucae identified three genes, $c d a A, c d a B$, and $c d a C$, encoding proteins with domains consistent with chitin deacetylases, including a Zn-binding motif and catalytic-site amino acid residues known to be required for peptidoglycan and chitin deacetylase activities in Streptococcus pneumoniae and Colletotrichum lindemuthianum, respectively (Blair et al. 2005, 2006). CdaA and CdaB also have predicted N-terminal signal peptides, as found in their homologs from $M$. oryzae and T. atroviride (Geoghegan and Gurr 2016; Kappel et al. 2020), suggesting they are both directed into the secretory pathway. However, $\mathrm{CdaB}$ also has a putative transmembrane domain, suggesting that it is localized to the outer membrane of the cell. None of these putative chitin deacetylases are predicted to have a C-terminal glycosylphosphatidylinositol anchor, which is a characteristic feature of the three Cryptococcus neoformans (Baker et al. 2007) and two Saccharomyces cerevisiae chitin deacetylases (Christodoulidou et al. 1996, 1999), which all group in a separate clade than the $M$. oryzae and $T$. atroviride chitin deacetylases (Geoghegan and Gurr 2016; Kappel et al. 2020). Given that there was a significant difference in $c d a A$ expression in planta compared with axenic culture (Hassing et al. 2019; Winter et al. 2018), we first generated a targeted deletion of this gene and analyzed both the axenic culture and plant-interaction phenotypes. While plants infected with the $\Delta c d a A$ mutants had no obvious whole-plant interaction phenotype, there was a distinct cellular phenotype. CLSM analysis revealed that the endophytic hyphae of this mutant were defective in intercalary growth within the leaves. Instead of the restrictive pattern of growth observed for WT (Christensen et al. 2008; Tanaka et al. 2006), hyphae of the $\Delta c d a A$ mutants had an irregular pattern of growth, were frequently branched, and occasionally formed dense convoluted structures. Interestingly, while patches of WGA-AF488 labeling indicative of increased chitin deposition were occasionally observed in endophytic $\Delta c d a A$ hyphae, most $\Delta c d a A$ hyphae did not exhibit this defect, suggesting deletion of this gene alone did not result in restoration of chitin to the endophytic cell wall.

To determine if the residual chitin deacetylating activity was due to redundancy with $\mathrm{CdaB}$, additional targeted gene deletions were performed to generate $\Delta c d a B$ mutants and $\Delta c d a A \Delta c d a B$ double mutants. While $c d a B$ is not differentially expressed in planta compared with axenic culture (Hassing et al. 2019; Winter et al. 2018), the plant interaction phenotype for $\Delta c d a B$ was much more severe than for both the $\Delta c d a A$ single and the $\Delta c d a A \Delta c d a B$ double mutant. Plants infected with the $\Delta c d a B$ mutant were frequently stunted, suggesting a severe antagonistic interaction between this mutant and the host grass, as previously observed for other symbiotic mutants (Becker et al. 2015; Scott et al. 2018; Tanaka et al. 2006). The absence of a whole-plant growth phenotype for the $\Delta c d a A$ and $\Delta c d a A \Delta c d a B$ mutants is consistent with their relative biomass being similar to the WT, whereas that of the $\triangle c d a B$ mutant is increased. The results also suggest that $c d a A$ is dominant to $c d a B$. However, at the cellular level, the hyphal growth phenotype was similar for all three mutants. The E. festucae $\Delta c d c 42$ mutant also lacks a whole-plant growth phenotype but does have a cellular phenotype of reduced host colonization and disrupted intercalary growth (Kayano et al. 2018). Even with deletion of both genes, chitin was still absent in most of the endophytic hyphal cell walls. The lack of detectable expression of $c d a C$ in these mutant backgrounds rules this out as an explanation for the phenotype observed. One possible explanation as to why chitin is still not detected in the cell walls of the $\Delta c d a A \Delta c d a B$ double mutant is deletion of these two genes somehow interferes with chitin as well as chitosan biosynthesis (Christodoulidou et al. 1999). 

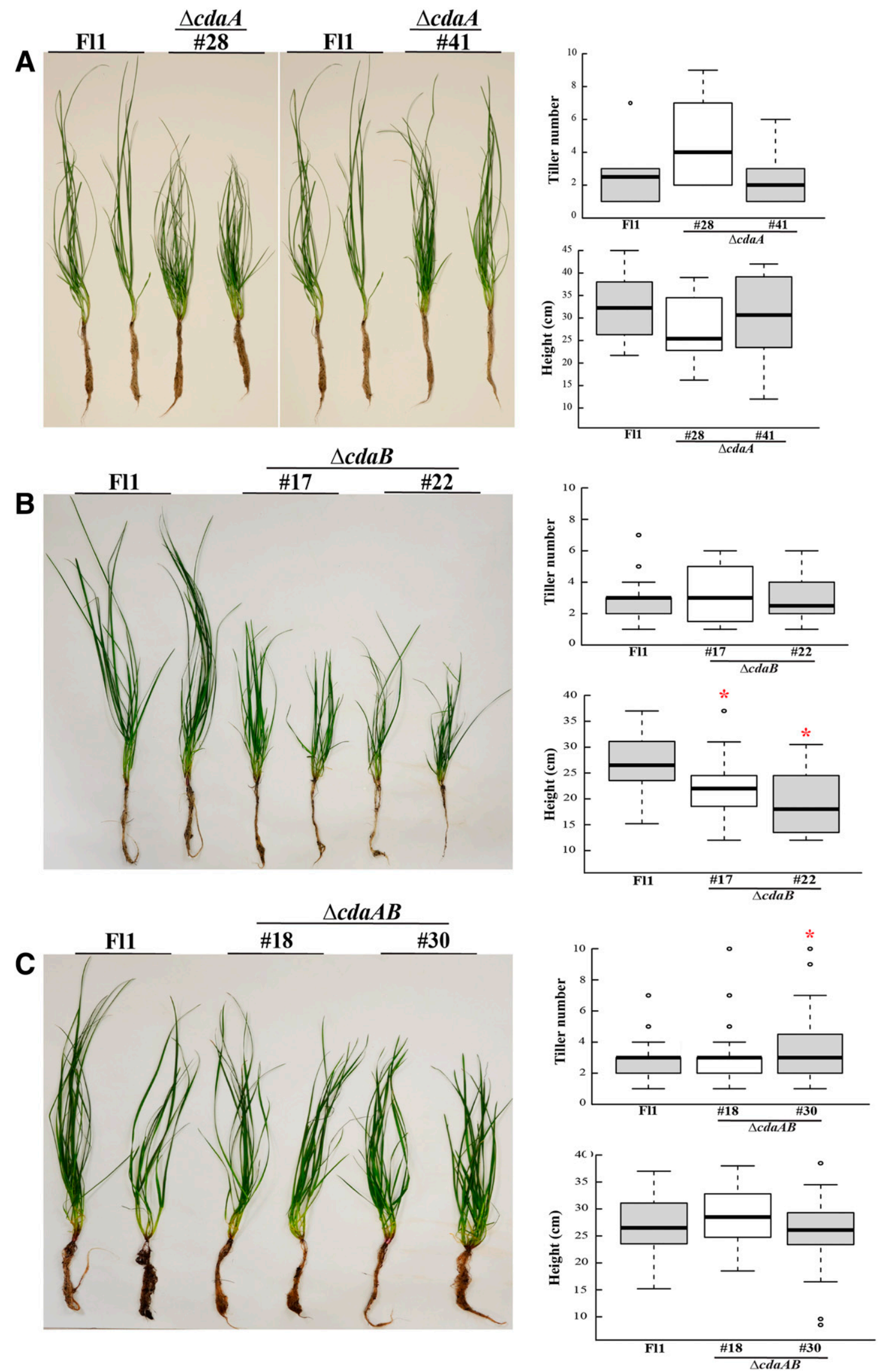

Fig. 4. Plant phenotype of Lolium perenne infected with Epichloë festucae wild type (WT), $\Delta c d a A, \Delta c d a B$, and $\Delta c d a A \Delta c d a B$ mutants. A through $\mathbf{C}$, Whole plant interaction phenotype of $L$. perenne plants infected with WT (Fl1), $\Delta c d a A, \Delta c d a B$, and $\Delta c d a A \Delta c d a B$ mutants 10 weeks after inoculation. Box plots show tiller number and tiller height of $L$. perenne plants infected with WT or $c d a$ mutant strains. Significant differences $(P<0.05$ as determined by a twotailed Student's $t$ test, $n \geq 10$ ) are indicated by a red asterisk $(*)$. Outliers are indicated by circles. 
Endophytic hyphae of all mutants had a very irregular pattern of growth marked by the presence of convoluted structures, particularly in the $\Delta c d a B$ mutant. Additionally, septa appeared markedly closer together than in the WT, indicating that individual hyphal cells were smaller. Unlike a number of previously isolated symbiotic mutants that showed a host-stunting phenotype (Charlton et al. 2012; Green et al. 2017; Tanaka et al. 2006, 2008, 2013; Takemoto et al. 2006), all $c d a$ mutants were still able to undergo cell-to-cell fusion of lateral branches, which is crucial for development of a hyphal network within the plant (Scott et al. 2018). The apparent reduction in hyphal cell length suggests there is a disruption to intercalary growth within the leaf tissue when chitosan synthesis is reduced. Chitosan may therefore have a key role in the remodeling of the cell wall of endophytic hyphae during intercalary growth, as hyphae are stretched and undergo septation in response to expansion of the leaf cells (Christensen et al. 2008; Voisey 2010). The positive charge of the chitosan could confer some affinity for the negative charge of the glucuronoarabinoxylan and pectin in the host cell walls (Geoghegan and Gurr 2016). The severe cellular phenotype observed with the chitin deacetylase mutants is consistent with these hypotheses and identifies a vital role for cell-wall remodeling in both fungal morphology and plant symbiosis.
Despite the strong whole-plant and cellular interaction phenotypes observed for the E. festucae cda mutants, no obvious phenotype difference to WT was observed when the $\Delta c d a A$ and $\Delta c d a B$ single mutants were grown in axenic culture. The radial growth and morphology of $\Delta c d a A$ and $\Delta c d a B$ mutants were also similar to WT. These mutants formed hyphal bundles, were able to undergo hyphal tip-to-side cell fusion, and formed characteristic coil-like structures from which conidiophores arise, with a morphology and frequency similar to WT (Becker et al. 2015; Scott et al. 2012). While the whole-colony morphology and radial growth phenotype of the $\Delta c d a A \Delta c d a B$ double mutant also appeared normal, microscopic examination of the cellular phenotype revealed that the cell-wall integrity of these mutants was compromised, as they frequently formed intrahyphal hyphae. This phenotype has been observed for a number of other symbiotic E. festucae mutants, including those involved in cell-wall integrity mitogen-activated protein kinase and calcineurin signaling (Becker et al. 2015; Green et al. 2017; Mitic et al. 2018), and for T. atroviride $\Delta c d a 1$ and $\Delta c h s 1$ mutants (Kappel et al. 2020).

In conclusion, this study highlights the very dynamic state of the chitin component of the E. festucae cell wall and how it rapidly changes during the developmental transitions that accompany the free-living to endophytic and the endophytic to epiphytic
F11

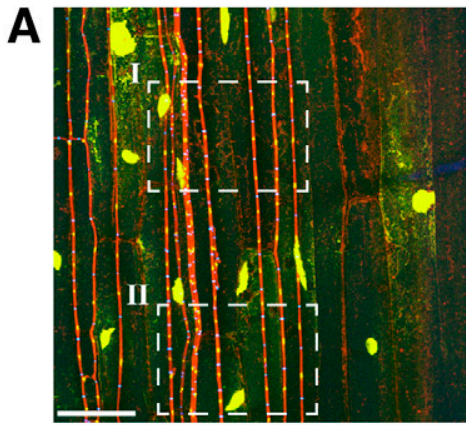

B

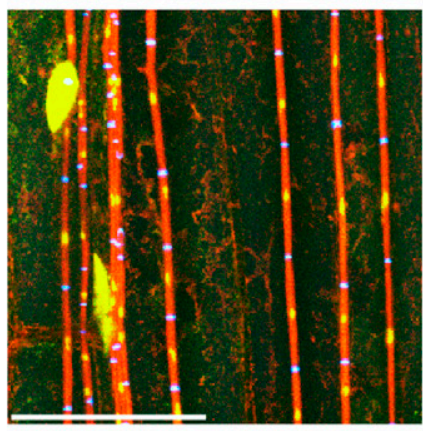

C

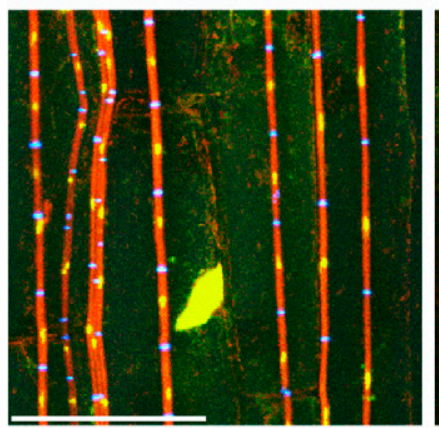

$\triangle c d a A \# 28$
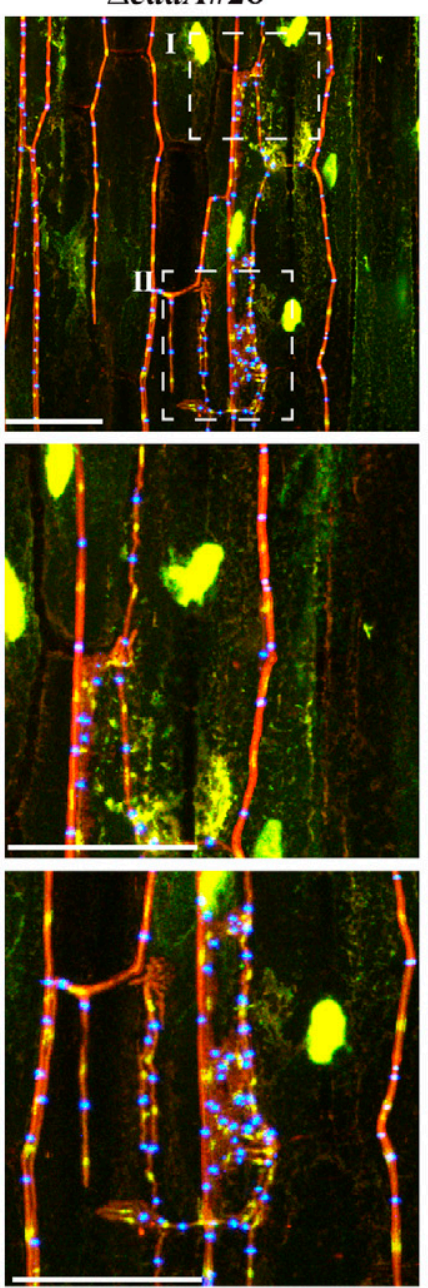

$\Delta c d a B \# 22$
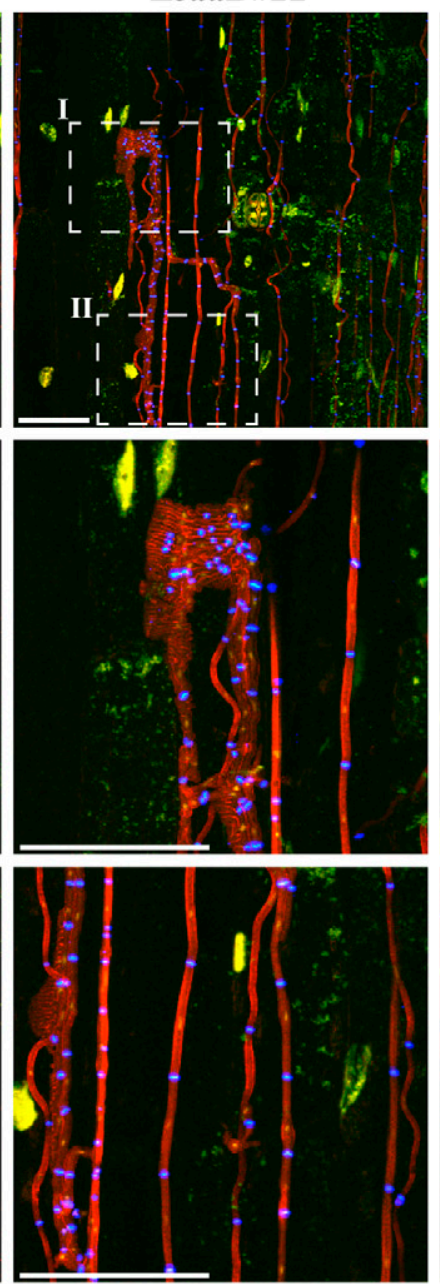

\section{$\triangle c d a A B \# 18$}
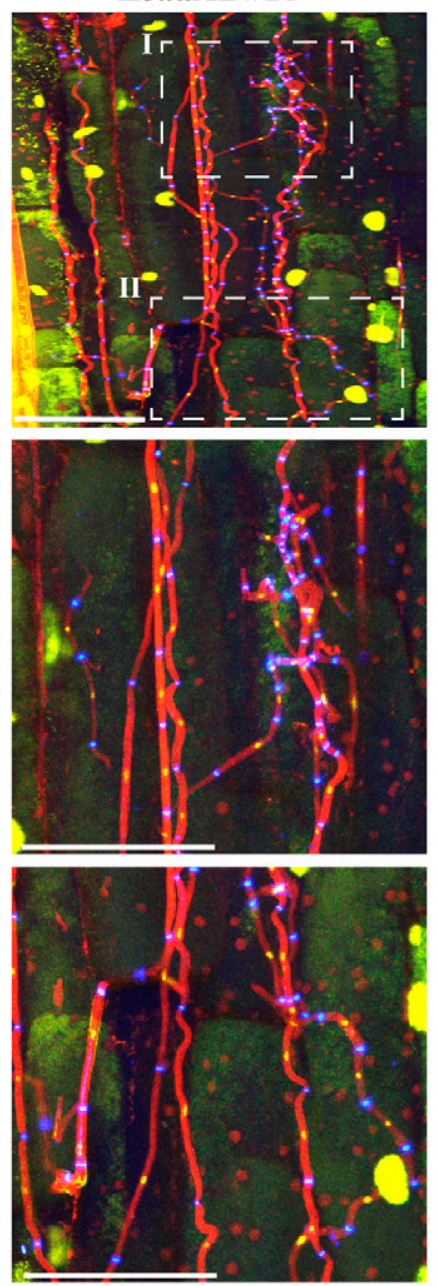

Fig. 5. In planta cellular phenotype of Lolium perenne infected with Epichlö festucae wild type (WT), $\Delta c d a A, \Delta c d a B$, and $\Delta c d a A \Delta c d a B$ mutants. A, Maximum intensity projections from longitudinal sections of $L$. perenne leaf sheath tissue infected with WT (Fl1), $\Delta c d a A, \Delta c d a B$, and $\Delta c d a A \Delta c d a B$ mutant strains 10 weeks postinoculation. Hyphae are stained with aniline blue (red), chitin in cell-wall septa are stained with wheat germ agglutinin-AlexaFluor 488 (blue), and fungal and plant nuclei are stained with propidium iodide (yellow). Bar $=50 \mu \mathrm{m}$. B, and $\mathbf{C}$, Higher magnification of sections I and II in panel A, showing normal hyphal compartment in WT, abnormal growth pattern of fungal hyphae, and increased hyphal branching in $c d a$ mutant strains, respectively. Images were generated by maximum intensity projection. Bar $=50 \mu \mathrm{m}$. 
lifestyle changes. Chitin deacetylase-catalyzed conversion of cellwall chitin to chitosan is crucial for maintaining a mutualistic symbiotic association between $E$. festucae and its grass host. It will be of considerable interest to determine how widespread this particular mechanism is among other symbiotic fungi for maintaining compatible interactions with their plant hosts.

\section{MATERIALS AND METHODS}

\section{Strains and growth condition.}

Cultures of Escherichia coli were grown overnight in LB (lysogeny broth) or on $1.5 \%$ LB agar containing $100 \mu \mathrm{g}$ ampicillin per milliliter, as previously described (Miller 1972). Cultures of $E$. festucae (Supplementary Table S3) were grown on $2.4 \%$ (wt/vol) PDA (1.5\% water) plates or in PD broth as previously described (Moon et al. 1999, 2000).

Plant growth and endophyte inoculation conditions.

Endophyte-free seedlings of perennial ryegrass (Lolium perenne cv. Samson) were inoculated with E. festucae as previously described (Latch and Christensen 1985). Plants were grown in root trainers in an environmentally controlled growth room at $22^{\circ} \mathrm{C}$ with a photoperiod of $16 \mathrm{~h}$ of light (about $100 \mu \mathrm{E}$ per square
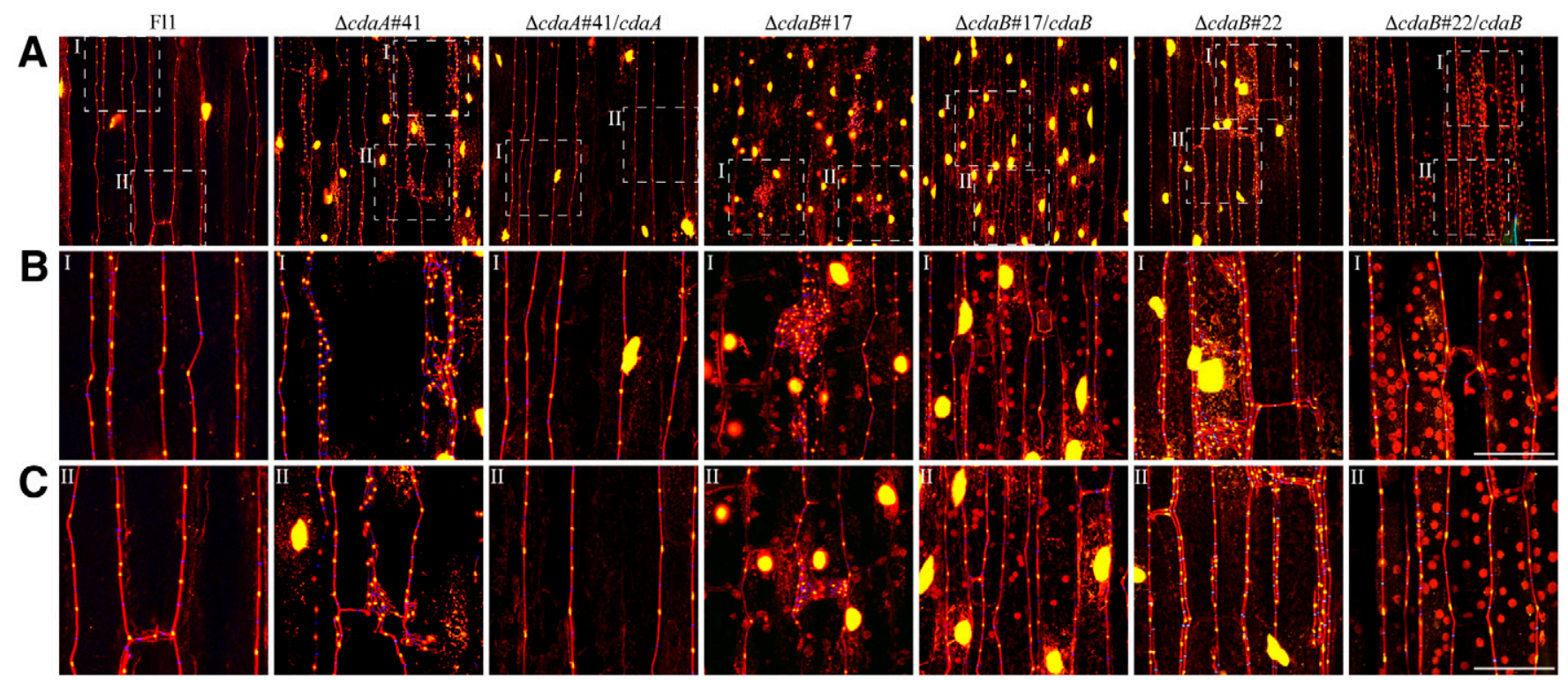

Fig. 6. Complementation of in planta cellular phenotype of Lolium perenne infected with Epichloe festucae $\Delta c d a A$ and $\Delta c d a B$ mutants. A, Maximum intensity projections from longitudinal sections of $L$. perenne leaf sheath tissue infected with wild-type Fl1 (WT), $\Delta c d a A, \Delta c d a B, \Delta c d a A / c d a A$, and $\Delta c d a B / c d a B$ mutant strains 10 weeks postinoculation. Hyphae are stained with aniline blue (red), chitin in cell-wall septa are stained with wheat germ agglutininAlexaFluor 488 (blue), and fungal and plant nuclei are stained with propidium iodide (yellow). Bar $=50 \mu \mathrm{m}$. B and C, Higher magnification of I and II, respectively, in the images in A showing normal hyphal growth in WT, abnormal growth pattern of fungal hyphae in $c d a$ mutant strains, and restoration of WT-like growth in the complementation mutants. Images were generated by maximum intensity projection. Bar $=50 \mu \mathrm{m}$.

\section{Fl1}

A

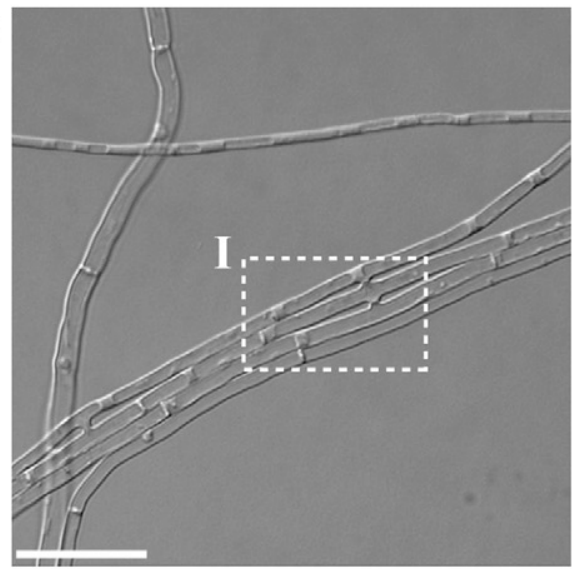

B

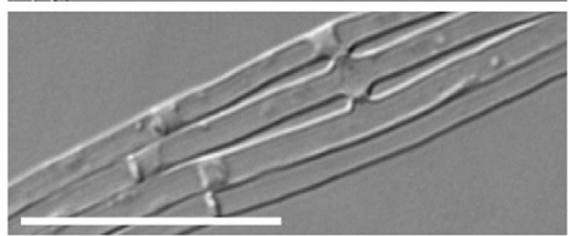

$\triangle c d a A B \# 18$
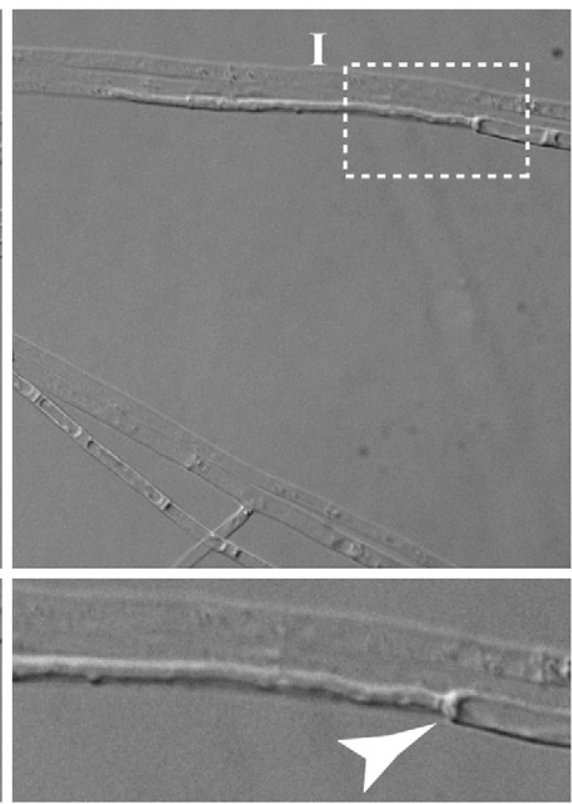

$\triangle c d a A B \# 30$
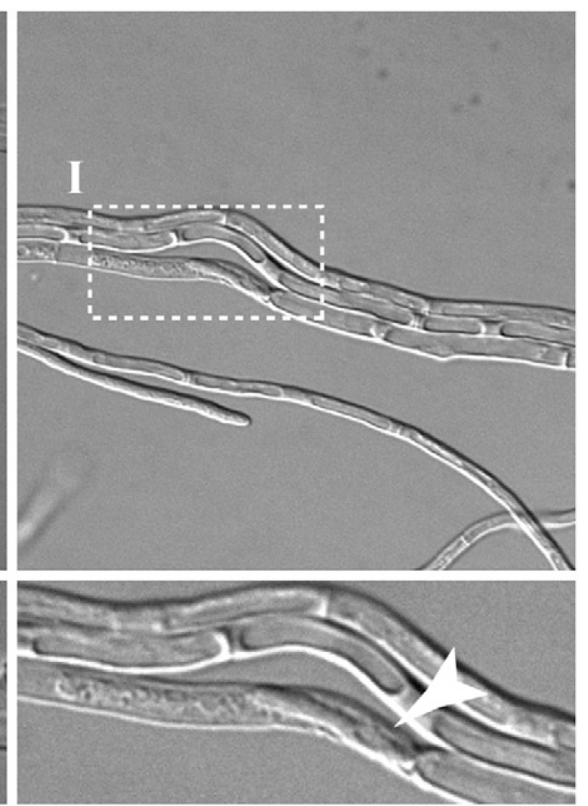

Fig. 7. Intrahyphal hyphae phenotype of the $\Delta c d a A \Delta c d a B$ mutant strains. A, Differential interference contrast images of wild type Fl1 and $\Delta c d a A \Delta c d a B$ mutant strains showing intrahyphal hyphae. B, Higher magnification of I sections in A, with white arrow heads pointing to intrahyphal hyphae. Bar $=20 \mu \mathrm{m}$. 
meter per second) and were tested by immunoblot at 8 wpi for the presence of the endophyte (Tanaka et al. 2005).

\section{DNA isolation, PCR, qPCR, reverse transcription qPCR (RT-qPCR) and sequencing.}

Plasmid DNA from Escherichia coli was extracted, using the High Pure plasmid isolation kit (Roche), according to manufacturer instructions. Fungal genomic DNA used for Southern digests was extracted from freeze-dried mycelium as previously described (Byrd et al. 1990). Standard PCR amplifications were performed with Taq DNA polymerase (Roche) as per manufacturer instructions. When high fidelity PCR products were required, proofreading polymerases such as Phusion (ThermoFisher Scientific) or Q5 (New England Biolabs, Inc.) were used as per manufacturer instructions. DNA sequencing of plasmids and PCR products were conducted at the Massey Genome Sequence Service (Palmerston North, New Zealand), using a 3730 DNA analyzer (Applied Biosystems) with BigDye Terminator Version 3.1 chemistry (Applied Biosystems).

For expression analysis by RT-qPCR, pseudostem tissues from 8-wpi plants were homogenized in liquid nitrogen with a mortar and pestle and RNA was isolated using TRIzol (Invitrogen) according to manufacturer instructions. One microgram of RNA was used for complementary DNA (cDNA) synthesis, using the QuantiTect RT kit (Qiagen), and cDNA was diluted threefold with Tris-EDTA (TE) buffer. qPCR was performed using the SsoFast EvaGreen supermix (Bio-Rad) on a LightCycler 480 System (Roche), according to manufacturer instructions. Standard curves were generated using the purified PCR product amplified by each primer pair. Absolute quantification RT-qPCR was performed using three biological replicates and two technical replicates for all samples. Transcript levels were normalized using the reference gene encoding elongation factor 2 (EfM3.021210).

Fungal biomass in infected plants was quantified at 8 wpi, using at least three biological replicates (eight for WT) from either 5-cm pseudostem sections taken from the base of each tiller or $10-\mathrm{cm}$ blade sections starting from the ligule. DNA was isolated as previously described (Liu et al. 2000) and was diluted 100-fold with TE buffer. Two microliters of this DNA was used as template for qPCR (SsoFast EvaGreen). Relative biomass was determined by qPCR analysis using the ratio of pacC, a single-copy endophyte gene encoding a transcription factor (Lukito et al. 2015), to LpCCR1, a single-copy plant gene encoding cinnamoyl-CoA reductase (McInnes et al. 2002). Standard curves were generated for each primer pair using purified PCR products of the primers, and absolute quantification qPCR was performed with two technical replicates per sample. Primers used in this study are listed in Supplementary Table S4.

\section{Generation of the $\Delta c d a A, \Delta c d a B$, and $\Delta c d a A \Delta c d a B$ mutants.}

The $c d a A$ replacement construct was prepared by Gibson Assembly (Gibson et al. 2009). The 5' 1,091-bp and 3' 1,084-bp sequences flanking $c d a A$ were amplified from an E. festucae Fl1 genomic DNA template, using PCR with primer pairs NN92/ NN93 and NN94/NN95, respectively. These DNA fragments were purified and assembled along with a 2,181-bp hygromycin resistance cassette (primers hph-F, pDB33_7) amplified from plasmid pDB48 and a linearized pRS426 vector to generate pNN05. The in vitro recombined DNA mixture was transformed into chemically competent Escherichia coli DH5 $\alpha$ cells, and ampicillin-resistant transformants were screened using Clonechecker (Life Technologies) for plasmids with restriction enzyme digest patterns predicted from in silico construction of pNN05. The sequence fidelity of the plasmid extracted from one of these clones was verified by DNA sequencing. The $c d a A$ replacement fragment contained within pNN05 was then excised by XmaI/HpaI digestion, was gel-purified, and was transformed into E. festucae protoplasts as described below, using hygromycin B for selection.

The $c d a B$ replacement construct was also prepared by Gibson Assembly (Gibson et al. 2009), using 2,359-bp $c d a B 5^{\prime}$ and 1,931-bp $c d a B 3^{\prime}$ fragments amplified from E. festucae Fl1 genomic DNA, using primer pairs NN151/NN152 and NN155/NN156, respectively, a 1,741-bp geneticin-resistance cassette amplified from pSF17.1 plasmid DNA, using primers NN153 and NN154, and a linearized pUC19 vector, with the resulting plasmid (pNN15) being screened and isolated as described above. The $c d a B$ replacement fragment contained within pNN15 was PCRamplified using primer pairs NN151/NN156, was gel-purified, and was transformed into E. festucae WT and $\Delta c d a A \# 41$ protoplasts as described below, using geneticin for selection to generate the $\Delta c d a B$ and $\Delta c d a A \Delta c d a B$ mutants.

\section{Fungal transformation.}

E. festucae protoplasts were prepared as previously described (Yelton et al. 1984) and were transformed with 2 to $5 \mu \mathrm{g}$ of circular or linearized plasmid DNA (Itoh et al. 1994). Transformants were selected on $1.5 \%$ RG media containing either hygromycin $(150 \mu \mathrm{g} / \mathrm{ml})$ or geneticin $(250 \mu \mathrm{g} / \mathrm{ml})$ and were nuclear-purified by three rounds of subculturing on selection medium (Young et al. 2005).

\section{DNA hybridization.}

High-quality E. festucae genomic DNA (1 to $1.5 \mu \mathrm{g}$ ) was digested overnight, using the appropriate restriction enzyme, was separated by agarose gel electrophoresis, and was transferred to a positively charged nylon membrane (Roche) (Southern 1975). DNA was crosslinked to the nylon membrane by UV irradiation for $2 \mathrm{~min}$, using a CEX-800 UV cross-linker $\left(120 \mathrm{~mJ} / \mathrm{cm}^{2}, 254\right.$ nm [Ultralum, Inc.]). DNA probes were labeled using the DIG High Prime dna labeling and detection starter kit (Roche), as per manufacturer instructions. Hybridizations were performed according to manufacturer instructions.

\section{Microscopy.}

Cultures to be analyzed by wide-field epifluorescence light microscopy were inoculated at the edge of a thin layer of $1.5 \%$ (wt/vol) water agar, were layered on top of a glass microscope slide embedded in $1.5 \%$ water agar, and were grown for 7 days. Square blocks were then extracted and placed onto new slides, were covered with a cover slip, and were analyzed using an epifluorescence microscope (Olympus IX83) with a 60× oil immersion objective, numerical aperture $(\mathrm{NA})=1.42$, outfitted with differential interference contrast optics. Calcofluor white was visualized using a U-MWU2 filter cube. All images were captured with a Retiga 6000M (QImaging) camera using a Bin $2 \times 2$ and controlled by cellSens software (Olympus).

Growth and morphology of hyphae in planta was determined by staining leaves with aniline blue diammonium salt (Sigma) and WGA-AF488 (Molecular Probes/Invitrogen) as follows: infected pseudostem tissue was incubated in $95 \%$ ( $\mathrm{vol} / \mathrm{vol}$ ) ethanol overnight at $4^{\circ} \mathrm{C}$, were then treated with $10 \%$ potassium hydroxide for $3 \mathrm{~h}$ or overnight at $4^{\circ} \mathrm{C}$. The tissue was washed three times in phosphate buffered saline (PBS) ( $\mathrm{pH} \mathrm{7.4)} \mathrm{and} \mathrm{was} \mathrm{incubated}$ in staining solution $(0.02 \%$ aniline blue, $10 \mu \mathrm{g}$ of WGA-AF488 per milliliter, and $0.02 \%$ Tween-20 [Invitrogen] in PBS [pH 7.4]) for $10 \mathrm{~min}$, followed by a 20 -min vacuum infiltration step. Hyphal growth and fungal cellular phenotypes were documented by CLSM, using a Leica SP5 DM6000B (Leica Microsystems) confocal microscope outfitted with a $40 \times$, NA 1.3 or $63 \times$ NA 1.4 oil immersion objective lens. WGA-AF488 was excited at $488 \mathrm{~nm}$ to detect chitin, and aniline blue was excited at $561 \mathrm{~nm}$ to detect $\beta$-1,3-glucan, with emissions collected at 498 to 551 
and 571 to $633 \mathrm{~nm}$, respectively. While aniline blue itself is not fluorescent, there is a minor fluorochrome component present, Sirofluor, that does fluoresce (Stone et al. 1984).

Fungal cell-wall chitin and chitosan distribution was analyzed in plant sheath samples using the enhanced green fluorescent protein-fused molecular probes CBP (Fuenzalida et al. 2014) and CAP (Nampally et al. 2012), respectively. The specificity of these probes for chitin and chitosan have been experimentally verified by previous studies (Fuenzalida et al. 2014; Nampally et al. 2012). Plant samples fixed in $95 \%$ ethanol were washed as described above and were incubated in staining solution containing $0.1 \mathrm{mg}$ of CAP per milliliter (1 mg of stock solution per milliliter in TEA buffer [ $20 \mathrm{mM}$ triethanolamine, $400 \mathrm{mM} \mathrm{NaCl}, 10 \%$ $\{\mathrm{vol} / \mathrm{vol}\}$ glycerol, $\mathrm{pH} 8.0], 0.02 \%$ [vol/vol] Tween 20 , and $0.02 \%$ [wt/vol] propidium iodide in PBS [pH 7.4]). Samples were vacuum-infiltrated for $30 \mathrm{~min}$ and were stored at $4{ }^{\circ} \mathrm{C}$ overnight, before analysis using CLSM. The WGA-AF488 chitin probe was excited using $488 \mathrm{~nm}$ light and its emission collected from 493 to $555 \mathrm{~nm}$. CBP and propidium iodide were excited at 488 and $561 \mathrm{~nm}$, respectively, and their emissions were collected at 493 to 555 and 571 to $684 \mathrm{~nm}$. The chitosan probe CAP was excited at $488 \mathrm{~nm}$ and emitted light was collected from 493 to $555 \mathrm{~nm}$. All imaging was performed with a 40× NA 1.3 oil objective lens and a step size of $1.2 \mu \mathrm{m}$. Images obtained from all microscopy approaches were produced with ImageJ (National Institutes of Health) software using the maximum intensity projections of five to 10 sections acquired at $1.2-\mu \mathrm{m}$ intervals.

\section{Bioinformatic analysis.}

E. festucae genes encoding chitin deacetylases were obtained from the Massey University Epichlö database (the E. festucae E2368 genome) and the domain structures of the encoded products were annotated using Pfam and InterProScan (v.5) (Quevillon et al. 2005; Zdobnov and Apweiler 2001). InterProScan lookup service (v.43.1), Phobius (v.1.01) (Käll et al. 2004), SignalP (v.4.1), and TMHMM (v.2.0c) were used, plus all software given by default with InterProScan (BlastProDom, FprintScan, HMMPIR, HMMPfam, HMMSmart, HMMTigr, ProfileScan, HAMAP, PatternScan, SuperFamily, Gene3D). Gene and protein sequences for E. festucae (Fl1) as well as other species were obtained from the genome databases curated by C. L. Schardl at the University of Kentucky (Schardl et al. 2013). The proposed gene models were validated based on hidden Markov model (HMM)-based gene structure prediction by FGENESH (Softberry). The Magnaporthe oryzea chitin deacetylase gene sequences (Geoghegan and Gurr 2016) used to perform tBlastn against the Fl1 genome were obtained through FungiDB, Fungal and Oomycete Genomics Resources.

Alignment of nucleotide and amino acid sequences were performed with ClustalW (Thompson et al. 1994), as provided with MacVector 14.5 (MacVector, Inc.) and using default parameters. The DNA and amino acid sequence alignments utilized for synteny analyses were performed using the MAFFT (v7.017) algorithm (Katoh and Standley 2013; Katoh et al. 2002).

\section{ACKNOWLEDGMENTS}

The authors thank J. Taylor and N. Minards (Manawatu Microscopy and Imaging Center) for technical advice.

\section{AUTHOR-RECOMMENDED INTERNET RESOURCES}

E. festucae Fl1 genome project database: http://csbio-l.csr.uky.edu/endophyte/cpindex.php FungiDB: https://fungidb.org/fungidb

Genome Projects at the University of Kentucky database:

http://csbio-l.csr.uky.edu/endophyte/cpindex.php

Softberry homepage: http://www.softberry.com

\section{LITERATURE CITED}

Baker, L. G., Specht, C. A., Donlin, M. J., and Lodge, J. K. 2007. Chitosan, the deacetylated form of chitin, is necessary for cell wall integrity in Cryptococcus neoformans. Eukaryot. Cell 6:855-867.

Becker, M., Becker, Y., Green, K., and Scott, B. 2016. The endophytic symbiont Epichlö̈ festucae establishes an epiphyllous net on the surface of Lolium perenne leaves by development of an expressorium, an appressorium-like leaf exit structure. New Phytol. 211:240-254.

Becker, Y., Eaton, C. J., Brasell, E., May, K. J., Becker, M., Hassing, B., Cartwright, G. M., Reinhold, L., and Scott, B. 2015. The fungal cellwall integrity MAPK cascade is crucial for hyphal network formation and maintenance of restrictive growth of Epichloë festucae in symbiosis with Lolium perenne. Mol. Plant-Microbe Interact. 28:69-85.

Blair, D. E., Hekmat, O., Schüttelkopf, A. W., Shrestha, B., Tokuyasu, K., Withers, S. G., and van Aalten, D. M. F. 2006. Structure and mechanism of chitin deacetylase from the fungal pathogen Colletotrichum lindemuthianum. Biochemistry 45:9416-9426.

Blair, D. E., Schüttelkopf, A. W., MacRae, J. I., and van Aalten, D. M. 2005. Structure and metal-dependent mechanism of peptidoglycan deacetylase, a streptococcal virulence factor. Proc. Natl. Acad. Sci. U.S.A. 102:15429-15434.

Blum, M., Chang, H. Y., Chuguransky, S., Grego, T., Kandasaamy, S., Mitchell, A., Nuka, G., Paysan-Lafosse, T., Qureshi, M., Raj, S., Richardson, L., Salazar, G. A., Williams, L., Bork, P., Bridge, A., Gough, J., Haft, D. H., Letunic, I., Marchler-Bauer, A., Mi, H., Natale, D. A., Necci, M., Orengo, C. A., Pandurangan, A. P., Rivoire, C., Sigrist, C. J. A., Sillitoe, I., Thanki, N., Thomas, P. D., Tosatto, S. C. E., Wu, C. H., Bateman, A., and Finn, R. D. 2021. The InterPro protein families and domains database: 20 years on. Nucleic Acids Res. 49 (D1):D344-D354.

Boller, T., and Felix, G. 2009. A renaissance of elicitors: Perception of microbe-associated molecular patterns and danger signals by patternrecognition receptors. Annu. Rev. Plant Biol. 60:379-406.

Boutrot, F., and Zipfel, C. 2017. Function, discovery, and exploitation of plant pattern recognition receptors for broad-spectrum disease resistance. Annu. Rev. Phytopathol. 55:257-286.

Bowman, S. M., and Free, S. J. 2006. The structure and synthesis of the fungal cell wall. BioEssays 28:799-808.

Byrd, A. D., Schardl, C. L., Songlin, P. J., Mogen, K. L., and Siegel, M. R. 1990. The $\beta$-tubulin gene of Epichloë typhina from perennial ryegrass (Lolium perenne). Curr. Genet. 18:347-354.

Charlton, N. D., Shoji, J. Y., Ghimire, S. R., Nakashima, J., and Craven, K. D. 2012. Deletion of the fungal gene soft disrupts mutualistic symbiosis between the grass endophyte Epichlö festucae and the host plant. Eukaryot. Cell 11:1463-1471.

Christensen, M. J., Ball, O. J.-P., Bennett, R. J., and Schardl, C. L. 1997. Fungal and host genotype effects on compatibility and vascular colonization by Epichlö̈ festucae. Mycol. Res. 101:493-501.

Christensen, M. J., Bennett, R. J., Ansari, H. A., Koga, H., Johnson, R. D., Bryan, G. T., Simpson, W. R., Koolaard, J. P., Nickless, E. M., and Voisey, C. R. 2008. Epichlö endophytes grow by intercalary hyphal extension in elongating grass leaves. Fungal Genet. Biol. 45:84-93.

Christensen, M. J., Bennett, R. J., and Schmid, J. 2002. Growth of Epichlö̈/Neotyphodium and p-endophytes in leaves of Lolium and Festuca grasses. Mycol. Res. 106:93-106.

Christensen, M. J., and Voissey, C. R. 2007. The biology of the endophyte/ grass partnership. Pages 123-133 in: Proceedings of the 6th International Symposium on Fungal Endophytes of Grasses. Grasslands Research and Practice Series No. 13, A. J. Popay and E. R. Thom, eds. New Zealand Grassland Association, Christchurch, New Zealand.

Christodoulidou, A., Bouriotis, V., and Thireos, G. 1996. Two sporulationspecific chitin deacetylase-encoding genes are required for the ascospore wall rigidity of Saccharomyces cerevisiae. J. Biol. Chem. 271: 31420-31425.

Christodoulidou, A., Briza, P., Ellinger, A., and Bouriotis, V. 1999. Yeast ascospore wall assembly requires two chitin deacetylase isozymes. FEBS Lett. 460:275-279.

Cord-Landwehr, S., Melcher, R. L., Kolkenbrock, S., and Moerschbacher, B. M. 2016. A chitin deacetylase from the endophytic fungus Pestalotiopsis sp. efficiently inactivates the elicitor activity of chitin oligomers in rice cells. Sci. Rep. 6:38018.

de Jonge, R., van Esse, H. P., Kombrink, A., Shinya, T., Desaki, Y., Bours, R., van der Krol, S., Shibuya, N., Joosten, M. H., and Thomma, B. P. 2010. Conserved fungal LysM effector Ecp6 prevents chitin-triggered immunity in plants. Science 329:953-955.

Eaton, C. J., Dupont, P.-Y., Solomon, P., Clayton, W., Scott, B., and Cox, M. P. 2015. A core gene set describes the molecular basis of mutualism 
and antagonism in Epichlö species. Mol. Plant-Microbe Interact. 28: 218-231.

El Gueddari, N. E., Rauchhaus, U., Moerschbacher, B. M., and Deising, H. B. 2002. Developmentally regulated conversion of surface-exposed chitin to chitosan in cell walls of plant pathogenic fungi. New Phytol. 156:103-112.

Erwig, L. P., and Gow, N. A. 2016. Interactions of fungal pathogens with phagocytes. Nat. Rev. Microbiol. 14:163-176.

Fesel, P. H., and Zuccaro, A. 2016. $\beta$-glucan: Crucial component of the fungal cell wall and elusive MAMP in plants. Fungal Genet. Biol. 90: 53-60.

Freytag, S., and Mendgen, K. 1991. Surface carbohydrates and cell wall structure of in vitro-induced uredospore infection structures of Uromyces viciae-fabae before and after treatment with enzymes and alkali. Protoplasma 161:94-103.

Fuenzalida, J. P., Weikert, T., Hoffmann, S., Vila-Sanjurjo, C., Moerschbacher, B. M., Goycoolea, F. M., and Kolkenbrock, S. 2014. Affinity protein-based FRET tools for cellular tracking of chitosan nanoparticles and determination of the polymer degree of acetylation. Biomacromolecules 15:2532-2539.

Fujikawa, T., Kuga, Y., Yano, S., Yoshimi, A., Tachiki, T., Abe, K., and Nishimura, M. 2009. Dynamics of cell wall components of Magnaporthe grisea during infectious structure development. Mol. Microbiol. 73:553570.

Fujikawa, T., Sakaguchi, A., Nishizawa, Y., Kouzai, Y., Minami, E., Yano, S., Koga, H., Meshi, T., and Nishimura, M. 2012. Surface $\alpha$-1,3-glucan facilitates fungal stealth infection by interfering with innate immunity in plants. PLoS Pathog. 8:e1002882.

Gao, F., Zhang, B. S., Zhao, J. H., Huang, J. F., Jia, P. S., Wang, S., Zhang, J., Zhou, J. M., and Guo, H. S. 2019. Deacetylation of chitin oligomers increases virulence in soil-borne fungal pathogens. Nat. Plants 5:1167-1176.

Geoghegan, I. A., and Gurr, S. J. 2016. Chitosan mediates germling adhesion in Magnaporthe oryzae and is required for surface sensing and germling morphogenesis. PLoS Pathog. 12:e1005703.

Gibson, D. G., Young, L., Chuang, R. Y., Venter, J. C., Hutchison, C. A., 3rd, and Smith, H. O. 2009. Enzymatic assembly of DNA molecules up to several hundred kilobases. Nat. Methods 6:343-345.

Gow, N. A. R., Latge, J. P., and Munro, C. A. 2017. The Fungal Cell Wall: Structure, Biosynthesis, and Function. Pages 267-292 in: The Fungal Kingdom. J. Heitman, B. J. Howlett, P. W. Crous, E. H. Stukenbrock, T. Y. James, N. A. R. Gow, eds. John Wiley \& Sons, Inc., New York.

Green, K. A., Becker, Y., Tanaka, A., Takemoto, D., Fitzsimons, H. L., Seiler, S., Lalucque, H., Silar, P., and Scott, B. 2017. SymB and SymC, two membrane associated proteins, are required for Epichlö̈ festucae hyphal cell-cell fusion and maintenance of a mutualistic interaction with Lolium perenne. Mol. Microbiol. 103:657-677.

Gubaeva, E., Gubaev, A., Melcher, R. L. J., Cord-Landwehr, S., Singh, R., El Gueddari, N. E., and Moerschbacher, B. M. 2018. 'Slipped sandwich' model for chitin and chitosan perception in Arabidopsis. Mol. Plant-Microbe Interact. 31:1145-1153.

Hassing, B., Winter, D., Becker, Y., Mesarich, C. H., Eaton, C. J., and Scott, B. 2019. Analysis of Epichlö festucae small secreted proteins in the interaction with Lolium perenne. PLoS One 14:e0209463.

Hinton, D. M., and Bacon, C. W. 1985. The distribution and ultrastructure of the endophyte of toxic tall fescue. Can. J. Bot. 63:36-42.

Hopke, A., Brown, A. J. P., Hall, R. A., and Wheeler, R. T. 2018. Dynamic fungal cell wall architecture in stress adaptation and immune evasion. Trends Microbiol. 26:284-295.

Itoh, Y., Johnson, R., and Scott, B. 1994. Integrative transformation of the mycotoxin-producing fungus, Penicillium paxilli. Curr. Genet. 25:508513 .

Kafetzopoulos, D., Martinou, A., and Bouriotis, V. 1993. Bioconversion of chitin to chitosan: Purification and characterization of chitin deacetylase from Mucor rouxii. Proc. Natl. Acad. Sci. U.S.A. 90:2564-2568.

Käll, L., Krogh, A., and Sonnhammer, E. L. 2004. A combined transmembrane topology and signal peptide prediction method. J. Mol. Biol. 338: 1027-1036.

Kappel, L., Münsterkötter, M., Sipos, G., Escobar Rodriguez, C., and Gruber, S. 2020. Chitin and chitosan remodeling defines vegetative development and Trichoderma biocontrol. PLoS Pathog. 16:e1008320.

Katoh, K., Misawa, K., Kuma, K., and Miyata, T. 2002. MAFFT: A novel method for rapid multiple sequence alignment based on fast Fourier transform. Nucleic Acids Res. 30:3059-3066.

Katoh, K., and Standley, D. M. 2013. MAFFT multiple sequence alignment software version 7: Improvements in performance and usability. Mol. Biol. Evol. 30:772-780.
Kayano, Y., Tanaka, A., and Takemoto, D. 2018. Two closely related Rho GTPases, Cdc42 and RacA, of the en-dophytic fungus Epichlö̈ festucae have contrasting roles for ROS production and symbiotic infection synchronized with the host plant. PLoS Pathog. 14: e 1006840 .

Latch, G. C. M., and Christensen, M. J. 1985. Artificial infection of grasses with endophytes. Ann. Appl. Biol. 107:17-24.

Latgé, J. P. 2007. The cell wall: A carbohydrate armour for the fungal cell. Mol. Microbiol. 66:279-290.

Latgé, J. P. 2010. Tasting the fungal cell wall. Cell. Microbiol. 12:863-872.

Liu, D., Coloe, S., Baird, R., and Pederson, J. 2000. Rapid mini-preparation of fungal DNA for PCR. J. Clin. Microbiol. 38:471.

Lukito, Y., Chujo, T., and Scott, B. 2015. Molecular and cellular analysis of the $\mathrm{pH}$ response transcription factor $\mathrm{PacC}$ in the fungal symbiont Epichlö̈ festucae. Fungal Genet. Biol. 85:25-37.

Ma, L. S., Wang, L., Trippel, C., Mendoza-Mendoza, A., Ullmann, S., Moretti, M., Carsten, A., Kahnt, J., Reissmann, S., Zechmann, B., Bange, G., and Kahmann, R. 2018. The Ustilago maydis repetitive effector Rsp3 blocks the antifungal activity of mannose-binding maize proteins. Nat. Commun. 9:1711.

McInnes, R., Lidgett, A., Lynch, D., Huxley, H., Jones, E., Mahoney, N., and Spangenberg, G. 2002. Isolation and characterization of a cinnamoyl-CoA reductase gene from perennial ryegrass (Lolium perenne). J. Plant Physiol. 159:415-422.

Miller, J. H. 1972. Experiments in Molecular Genetics. Cold Spring Harbor Laboratory Press, New York.

Mitic, M., Berry, D., Brasell, E., Green, K., Young, C. A., Saikia, S., Rakonjac, J., and Scott, B. 2018. Disruption of calcineurin catalytic subunit (cnaA) in Epichlö festucae induces symbiotic defects and intrahyphal hyphae formation. Mol. Plant Pathol. 19:1414-1426.

Moon, C. D., Scott, B., Schardl, C. L., and Christensen, M. J. 2000. The evolutionary origins of Epichlö̈ endophytes from annual ryegrasses. Mycologia 92:1103-1118.

Moon, C. D., Tapper, B. A., and Scott, B. 1999. Identification of Epichlö endophytes in planta by a microsatellite-based PCR fingerprinting assay with automated analysis. Appl. Environ. Microbiol. 65:1268-1279.

Moy, M., Belanger, F., Duncan, R., Freehoff, A., Leary, C., Meyer, W., Sullivan, R., and J.F., W.J. 2000. Identification of epiphyllous mycelial nets on leaves of grasses infected by clavicipitaceous endophytes. Symbiosis 28:291-302.

Nampally, M., Moerschbacher, B. M., and Kolkenbrock, S. 2012. Fusion of a novel genetically engineered chitosan affinity protein and green fluorescent protein for specific detection of chitosan in vitro and in situ. Appl. Environ. Microbiol. 78:3114-3119.

Pérez, P., and Ribas, J. C. 2004. Cell wall analysis. Methods 33:245-251.

Quevillon, E., Silventoinen, V., Pillai, S., Harte, N., Mulder, N., Apweiler, R., and Lopez, R. 2005. InterProScan: Protein domains identifier. Nucleic Acids Res. 33:W116-W120.

Sánchez-Vallet, A., Mesters, J. R., and Thomma, B. P. 2015. The battle for chitin recognition in plant-microbe interactions. FEMS Microbiol. Rev. 39:171-183.

Schardl, C. L., Leuchtmann, A., and Spiering, M. J. 2004. Symbioses of grasses with seedborne fungal endophytes. Annu. Rev. Plant Biol. 55: 315-340.

Schardl, C. L., Scott, B., Florea, S., and Zhang, D. 2009. Epichloe endophytes: clavicipitaceous symbionts of grasses. Pages 275-306 in: Plant Relationships. The Mycota (A Comprehensive Treatise on Fungi as Experimental Systems for Basic and Applied Research).Vol. 5. H. B. Deising, ed. Springer-Verlag, Berlin.

Schardl, C. L., Young, C. A., Hesse, U., Amyotte, S. G., Andreeva, K., Calie, P. J., Fleetwood, D. J., Haws, D. C., Moore, N., Oeser, B., Panaccione, D. G., Schweri, K. K., Voisey, C. R., Farman, M. L., Jaromczyk, J. W., Roe, B. A., O'Sullivan, D. M., Scott, B., Tudzynski, P., An, Z., Arnaoudova, E. G., Bullock, C. T., Charlton, N. D., Chen, L., Cox, M., Dinkins, R. D., Florea, S., Glenn, A. E., Gordon, A., Güldener, U., Harris, D. R., Hollin, W., Jaromczyk, J., Johnson, R. D., Khan, A. K., Leistner, E., Leuchtmann, A., Li, C., Liu, J., Liu, J., Liu, M., Mace, W., Machado, C., Nagabhyru, P., Pan, J., Schmid, J., Sugawara, K., Steiner, U., Takach, J. E., Tanaka, E., Webb, J. S., Wilson, E. V., Wiseman, J. L., Yoshida, R., and Zeng, Z. 2013. Plant-symbiotic fungi as chemical engineers: Multi-genome analysis of the clavicipitaceae reveals dynamics of alkaloid loci. PLoS Genet. 9: e1003323.

Scott, B., Becker, Y., Becker, M., and Cartwright, G. 2012. Morphogenesis, growth and development of the grass symbiont Epichlö festucae. Pages 243-264 in: Morphogenesis and Pathogenicity in Fungi, J. P. Martin and A. Di Pietro, eds. Springer-Verlag, Heidelberg. 
Scott, B., Green, K., and Berry, D. 2018. The fine balance between mutualism and antagonism in the Epichlö̈ festucae-grass symbiotic interaction. Curr. Opin. Plant Biol. 44:32-38.

Southern, E. M. 1975. Detection of specific sequences among DNA fragments separated by gel electrophoresis. J. Mol. Biol. 98:503-517.

Stone, B. A., Evans, N. A., Bonig, I., and Clarke, A. E. 1984. The application of sirofluor, a chemically defined fluorochrome from aniline blue for the histochemical detection of callose. Protoplasma 122:191-195.

Takemoto, D., Tanaka, A., and Scott, B. 2006. A p67Phox-like regulator is recruited to control hyphal branching in a fungal-grass mutualistic symbiosis. Plant Cell 18:2807-2821.

Tanaka, A., Cartwright, G. M., Saikia, S., Kayano, Y., Takemoto, D., Kato, M., Tsuge, T., and Scott, B. 2013. ProA, a transcriptional regulator of fungal fruiting body development, regulates leaf hyphal network development in the Epichloë festucae-Lolium perenne symbiosis. Mol. Microbiol. 90:551-568.

Tanaka, A., Christensen, M. J., Takemoto, D., Park, P., and Scott, B. 2006. Reactive oxygen species play a role in regulating a fungus-perennial ryegrass mutualistic interaction. Plant Cell 18:1052-1066.

Tanaka, A., Takemoto, D., Chujo, T., and Scott, B. 2012. Fungal endophytes of grasses. Curr. Opin. Plant Biol. 15:462-468.

Tanaka, A., Takemoto, D., Hyon, G. S., Park, P., and Scott, B. 2008. NoxA activation by the small GTPase RacA is required to maintain a mutualistic symbiotic association between Epichlö̈ festucae and perennial ryegrass. Mol. Microbiol. 68:1165-1178.

Tanaka, A., Tapper, B. A., Popay, A., Parker, E. J., and Scott, B. 2005. A symbiosis expressed non-ribosomal peptide synthetase from a mutualistic fungal endophyte of perennial ryegrass confers protection to the symbiotum from insect herbivory. Mol. Microbiol. 57:1036-1050.

Thompson, J. D., Higgins, D. G., and Gibson, T. J. 1994. CLUSTAL W: Improving the sensitivity of progressive multiple sequence alignment through sequence weighting, position-specific gap penalties and weight matrix choice. Nucleic Acids Res. 22:4673-4680.

van Esse, H. P., Bolton, M. D., Stergiopoulos, I., de Wit, P. J., and Thomma, B. P. 2007. The chitin-binding Cladosporium fulvum effec- tor protein Avr4 is a virulence factor. Mol. Plant-Microbe Interact. 20: 1092-1101.

Vander, P., Vårum, K. M., Domard, A., El Gueddari, N. E., and Moerschbacher, B. M. 1998. Comparison of the ability of partially N-acetylated chitosans and chitooligosaccharides to elicit resistance reactions in wheat leaves. Plant Physiol. 118:1353-1359.

Voisey, C. R. 2010. Intercalary growth in hyphae of filamentous fungi. Fungal Biol. Rev. 24:123-131.

Wawra, S., Fesel, P., Widmer, H., Timm, M., Seibel, J., Leson, L., Kesseler, L., Nostadt, R., Hilbert, M., Langen, G., and Zuccaro, A. 2016. The fungal-specific $\beta$-glucan-binding lectin FGB1 alters cell-wall composition and suppresses glucan-triggered immunity in plants. Nat. Commun. 7:13188.

Winter, D. J., Ganley, A. R. D., Young, C. A., Liachko, I., Schardl, C. L., Dupont, P. Y., Berry, D., Ram, A., Scott, B., and Cox, M. P. 2018. Repeat elements organise 3D genome structure and mediate transcription in the filamentous fungus Epichlö festucae. PLoS Genet. 14: e1007467.

Xu, Q., Wang, J., Zhao, J., Xu, J., Sun, S., Zhang, H., Wu, J., Tang, C., Kang, Z., and Wang, X. 2020. A polysaccharide deacetylase from Puccinia striiformis $\mathrm{f}$. sp. tritici is an important pathogenicity gene that suppresses plant immunity. Plant Biotechnol. J. 18:1830-1842.

Yelton, M. M., Hamer, J. E., and Timberlake, W. E. 1984. Transformation of Aspergillus nidulans by using a trpC plasmid. Proc. Natl. Acad. Sci. U.S.A. 81:1470-1474.

Young, C. A., Bryant, M. K., Christensen, M. J., Tapper, B. A., Bryan, G. T., and Scott, B. 2005. Molecular cloning and genetic analysis of a symbiosis-expressed gene cluster for lolitrem biosynthesis from a mutualistic endophyte of perennial ryegrass. Mol. Genet. Genomics 274: 13-29.

Zdobnov, E. M., and Apweiler, R. 2001. InterProScan-An integration platform for the signature-recognition methods in InterPro. Bioinformatics 17:847-848.

Zipfel, C., and Oldroyd, G. E. 2017. Plant signalling in symbiosis and immunity. Nature 543:328-336. 